\title{
Nitroxide-Mediated Radical Polymerization of Styrene in Emulsion
}

\author{
Jizhuang CAO, Junpo HE, Chengming LI, and Yuliang YANG ${ }^{\dagger}$ \\ Department of Macromolecular Science, The Key Laboratory of Macromolecular Engineering, SEDC, \\ Fudan University, Shanghai 200433, China
}

(Received July 3, 2000; Accepted October 3, 2000)

\begin{abstract}
The emulsion polymerizations of styrene in the presence of a variety of TEMPO derivatives were investigated. Among the TEMPO derivatives we studied, 4-acetoxy-2,2,6,6-tetramethylpiperidine-1-oxy (ATEMPO) was a suitable candidate for a living radical polymerization in emulsion, because it provided an optimized balance between hydrophilic and hydrophobic character. For the emulsion polymerization of styrene in the presence of 4-hydroxy-2,2,6,6tetramethylpiperidine-1-oxy (HTEMPO), however, the slow initiation in aqueous phase due to the strong hydrophilic character of HTEMPO, hindered styrene polymerized in a living fashion. The emulsion polymerization of styrene in the presence of 4-benzoyloxy-2,2,6,6-tetramethyl-piperidine-1-oxy (BTEMPO) who was absolutely rich in organic phase, was uncontrolled and identical to conventional radical polymerization.

KEY WORDS Nitroxide-Mediated / Living Radical Polymerization / Emulsion / TEMPO Derivative / Hydrophilic / Hydrophobic /
\end{abstract}

During the last few years, the synthesis of welldefined polymers by living free radical polymerization (LFRP) mediated by stable nitroxyl radicals (SNRs) such as TEMPO (2,2,6,6-tetramethylpiperidinyl-1-oxy) have attracted much attention. ${ }^{1-9}$ The key to the success of the SNR-mediated radical polymerization is the reversible termination of a polymer radical, $R(j)^{\bullet}$, with an $\mathrm{SNR}, \mathrm{N}^{\bullet}$, to form an adduct, $\mathrm{NR}(\mathrm{j})$, a dormant species:

$$
\mathrm{N}^{\bullet}+\mathrm{R}^{\bullet}(\mathrm{j}) \frac{k_{\mathrm{f}}}{k_{-\mathrm{f}}} \mathrm{NR}(\mathrm{j})
$$

where $k_{\mathrm{f}}$ and $k_{-\mathrm{f}}$ are the rate constants of combination and dissociation, respectively. The role of the nitroxide in these systems is to mediate the reactivity of the growing polymer chain by forming a thermally unstable alkoxyamine chain end. Dissociation of the alkoxyamine chain end under the polymerization conditions regenerates the radical chain end, which can then add more monomer units before being capped again by nitroxide. Accurate control over number-average molar mass, ${ }^{1}$ chain ends, ${ }^{2}$ and macromolecular architecture ${ }^{3-7}$ has been successfully applied to a variety of monomer/comonomer systems. ${ }^{8,9}$

The main advantage of living free radical polymerization with respect to living ionic polymerization is that reactions can be performed in the presence of water. It is therefore possible to carry out polymerization in aqueous dispersed system, including suspension polymerization, ${ }^{10-12}$ dispersion polymerization, ${ }^{13-15}$ emulsion polymerization $^{16-19}$ and miniemulsion polymerization..$^{20,21}$ The most obvious technical advantages of emulsion polymerization $^{22}$ such as ease of temperature control, environmentally safe, etc., indicate a good future of living free radical emulsion polymerization. On LFRP in emulsion, some papers for nitroxide-mediated ${ }^{16,18}$ and ATRP systems ${ }^{19}$ have been published. However, till now few papers on the mechanism of living free radical emulsion polymerization have been reported and more works are necessary.

${ }^{\dagger}$ To whom all correspondence should be addressed.
In this paper, the interest is focused on the role of stable nitroxyl radicals in emulsion polymerization in the presence of SNRs. Therefore, TEMPO and several TEMPO derivatives (Scheme 1), including HTEMPO (4hydroxy-2,2,6,6-tetramethylpiperidine-1-oxy), ATEMPO (4-acetoxy-2,2,6,6-tetramethylpiperidine-1-oxy), and BTEMPO (4-benzoyloxy-2,2,6,6-tetramethylpiperidine1-oxy), are employed to investigate mechanism and kinetic behavior of nitroxide-mediated radical polymerization in emulsion. The balance between hydrophilic and hydrophobic character of nitroxide will influence the polymerization behavior.

\section{EXPERIMENTAL}

\section{Materials}

Styrene was freshly distilled before use. Potassium persulfate $\left(\mathrm{K}_{2} \mathrm{~S}_{2} \mathrm{O}_{8}\right)$ was recrystallized from de-ionized water and azobisisobutyronitrile (AIBN) was recrystallized from chloroform/methanol. ATEMPO and BTEMPO were prepared using a method described previously. ${ }^{23}$ HTEMPO was received from BASF and recrystallized from cyclohexane before use. TEMPO was purchased from Aldrich and Sodium lauryl sulfate (SDS) was purchased from Shanghai Chemical Agent Company.

\section{Measurements}

Gel Permeation Chromatography (GPC) was per-<smiles>CC(=O)OC1CC(C)(C)N([O])C(C)(C)C1</smiles><smiles>CC1(C)CC(OC(=O)c2ccccc2)CC(C)(C)N1[O]</smiles><smiles>CC1(C)CC(O)CC(C)(C)N1[O]</smiles><smiles>CC1(C)CCCC(C)(C)N1[O]</smiles>

ATEMPO

BTEMPO

HTEMPO

TEMPO 


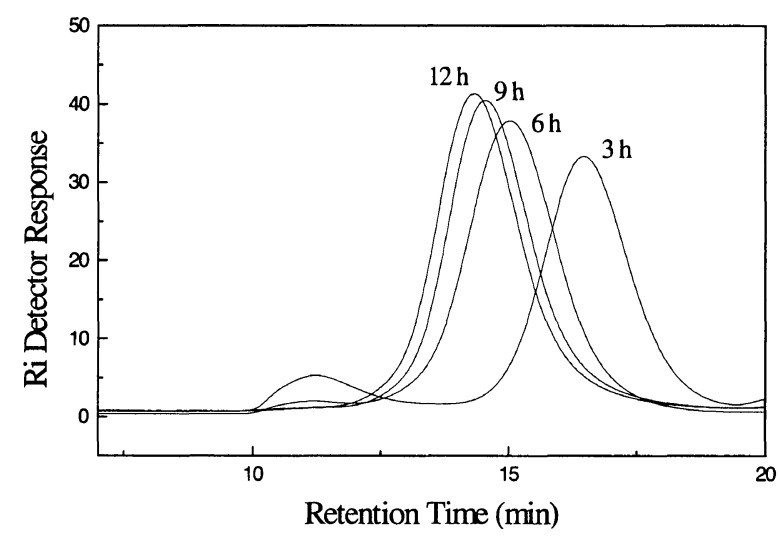

Figure 1. GPC traces in ATEMPO-mediated emulsion polymerization at $120^{\circ} \mathrm{C}$, in which $15.8 \mathrm{~g}$ styrene, $30 \mathrm{~g} \mathrm{H}_{2} \mathrm{O}, 0.105 \mathrm{~g}$ SDS, $0.1026 \mathrm{~g} \mathrm{~K}_{2} \mathrm{~S}_{2} \mathrm{O}_{8}$ has been used and $\left[\mathrm{K}_{2} \mathrm{~S}_{2} \mathrm{O}_{8}\right]_{0}$ : [ATEMPO] $]_{0}=1: 1.1$.

formed on a Waters instrument equipped with three Waters Styragel columns (pore size: $10^{2}, 10^{3}$, and $10^{4} \AA$ ) in

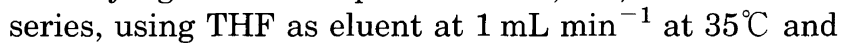
polystyrene as the standard. Particle size and particle morphology were measured by using scanning electron microscopy (SEM, XL 30, Philips). The saturation concentrations of various nitroxides in aqueous and styrene were determined by UV-spectroscopy (756 MC, Shanghai Analytical Instrument Co.).

\section{Polymerizations}

Emulsion polymerization of styrene was performed at monomer to water ratio of $1 / 2$ in the presence of TEMPO and TEMPO derivatives, while potassium persulfate $\left(\mathrm{K}_{2} \mathrm{~S}_{2} \mathrm{O}_{8}\right)$ was used as initiator and sodium lauryl sulfate (SDS) as surfactant. The reaction mixture was poured into the reactor, degassed, and purged with nitrogen three times. Then the emulsion polymerization was carried out in an asbestos jacketed high-pressure reactor $(0.2 \mathrm{~L})$ under nitrogen atmosphere of $2.5 \mathrm{~atm}$., theremostated at $120^{\circ} \mathrm{C}$ and equipped with a magnetic stirrer. The stirring speed was kept at $300 \mathrm{rpm}$. After polymerization, the emulsion breaking of polymer latices were carried out with $10 \%$ lithium chloride aqueous solution and $1 \mathrm{~mol} \mathrm{~L}^{-1}$ hydrochloric acid. The products were washed by methanol and de-ionized water, followed by precipitation to determinate conversion and numberaverage molar mass. In addition, conventional emulsion polymerization of styrene without nitroxides was carried out at $70^{\circ} \mathrm{C}$, whose recipe is same to that of nitroxidemediated emulsion polymerization except nitroxides.

For comparison, the nitroxide-mediated radical polymerization in bulk was carried out as follows. A solution of styrene, AIBN and TEMPO or TEMPO derivative was heated at $120^{\circ} \mathrm{C}$ under nitrogen atmosphere. An aliquot of about $0.5 \mathrm{~mL}$ of the mixture was extracted at a predetermined time and dried in vacuum at $50^{\circ} \mathrm{C}$. The weight loss gave the monomer content at the time when the sample was taken.

\section{RESULTS AND DISCUSSION}

The emulsion polymerizations of styrene were carried out in the presence of TEMPO or TEMPO derivatives at

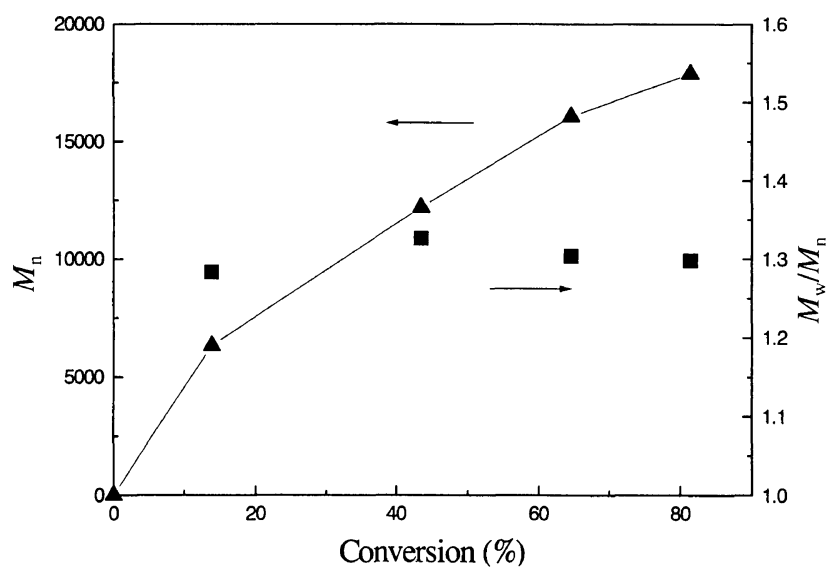

Figure 2. Variations of number average number-average molar mass and polydispersity index for emulsion polymerization of styrene mediated by ATEMPO.

$120^{\circ} \mathrm{C}$ in an asbestos jacketed high-pressure reactor $(0.2$ L), while sodium lauryl sulfate (SDS) was used as surfactant. The styrene: $\mathrm{K}_{2} \mathrm{~S}_{2} \mathrm{O}_{8}$ and SNR: $\mathrm{K}_{2} \mathrm{~S}_{2} \mathrm{O}_{8}$ were kept constant at $400: 1$ and $1.1: 1$, respectively.

Figure 1 illustrates the GPC trace of emulsion polymerization of styrene in the presence of ATEMPO. The GPC curves are shifted toward low retention time as the reaction time increases. Number-average molar mass $\left(M_{\mathrm{n}}\right)$ from 6300 to $17900 \mathrm{~g} \mathrm{~mol}^{-1}$ and polydispersity in$\operatorname{dex}\left(M_{\mathrm{w}} / M_{\mathrm{n}}\right)$ in the range of $1.28-1.33$ were evaluated and shown in Table I. As expected for a living polymerization, $M_{\mathrm{n}}$ increases linearly with conversion in spite its value is lower than that of theoretical prediction. Moreover, the polydispersity index of ATEMPO-mediated system is evidently lower than that of conventional emulsion polymerization. Figure 2 clearly indicates that it is possible to control the molar mass values of polystyrene in emulsion polymerization by using ATEMPO as stable nitroxyl radical. There is no measurable flocculation during the polymerization and the reaction is reproducible. The emulsion is stable and can be stored at room temperature for several days. It should be noted that the minor peaks corresponding to high molecular weight for 3-h polymerization and 6 -h polymerization have been excluded in our calculation. The area of high molecular weight peak takes only $9.6 \%, 4.2 \%$, and $2.5 \%$ of the total peak area for 3 -h, 6 -h, and 9 -h polymerization, respectively. It hints that the most of high molecular weight chains are formed at initial stage of polymerization. As $\mathrm{K}_{2} \mathrm{~S}_{2} \mathrm{O}_{8}$ decompose rapidly at high reaction temperature, a lot of nitroxide-free micelles formed from excessive growing radicals directly rather than from ATEMPOcapped oligomers. Therefore, an uncontrolled chain growth is expected. With the reaction proceeds, the most of uncontrolled growing chains in the micelles which are formed from growing radicals have been irreversibly terminated or capped by ATEMPO diffusing from aqueous, while the chains in the micelles which are formed from ATEMPO-capped oligomers still keep alive. As a result, the most of monomers will diffuse into the micelles in the presence of ATEMPO rather than those in the absence of ATEMPO and the controlled chain growth take a dominant role.

Figure 3 illustrates the GPC trace of emulsion polym- 
Table I. Nitroxide-mediated radical polymerization of styrene in emulsion

\begin{tabular}{|c|c|c|c|c|c|}
\hline \multirow{2}{*}{ Nitroxide } & Time & Conversion & \multirow{2}{*}{$M_{\mathrm{n}}$} & \multirow{2}{*}{$M_{\mathrm{w}} / M_{\mathrm{n}}$} & \multirow{2}{*}{$M_{\mathrm{n}}$, calc. $^{\mathrm{a}}$} \\
\hline & $\mathrm{h}$ & $\%$ & & & \\
\hline \multirow[t]{4}{*}{ ATEMPO $^{\mathrm{b}}$} & 3 & 13.8 & 6300 & 1.28 & 4800 \\
\hline & 6 & 43.4 & 12200 & 1.33 & 15000 \\
\hline & 9 & 64.6 & 16000 & 1.30 & 22400 \\
\hline & 12 & 81.4 & 17900 & 1.29 & 28200 \\
\hline \multirow[t]{4}{*}{ HTEMPO $^{c}$} & 3 & 1.0 & 20800 & 2.23 & ca. 400 \\
\hline & 6 & 24.0 & 20200 & 1.44 & 8300 \\
\hline & 9 & 30.6 & 24200 & 1.44 & 10600 \\
\hline & 12 & 37.2 & 29500 & 1.42 & 12900 \\
\hline \multirow[t]{4}{*}{ BTEMPO } & 1 & 69.4 & 21200 & 2.83 & 24100 \\
\hline & 3 & 74.7 & 23300 & 2.17 & 25900 \\
\hline & 6 & 80.5 & 19500 & 3.25 & 27900 \\
\hline & 9 & 93.9 & 25700 & 2.52 & 32500 \\
\hline \multirow[t]{4}{*}{ TEMPO } & 3 & 7.5 & 14300 & 2.32 & 2600 \\
\hline & 6 & 19.8 & 13800 & 1.67 & 6900 \\
\hline & 9 & 45.8 & 14400 & 1.80 & 15900 \\
\hline & 12 & 54.8 & 18500 & 1.71 & 19000 \\
\hline Without Nitroxides $^{\mathrm{d}}$ & 2 & $>90.0$ & 72600 & 1.89 & - \\
\hline
\end{tabular}

${ }^{\mathrm{a}}$ The predication of molecular weight is according to: $M_{\mathrm{n} \text {, calc. }} \cong \Delta[\mathrm{M}] /\left(\left[\mathrm{R}^{\bullet}\right]+[\mathrm{R}-\mathrm{N}]\right)$ (ref 24$) ;{ }^{\mathrm{b}}$ The minor peaks corresponding to high molecular weight for 3-h and 6-h polymerization in Figure 1 have been excluded in calculation; ${ }^{\mathrm{c}}$ The oligomers are evidently discerned in the GPC trace for the low conversion, whose molecular weights are far below the detection limit of GPC in our lab. They have been excluded in calculation and the data of $M_{\mathrm{n}}$ for 3-h is only for comparison; ${ }^{\mathrm{d}}$ The conventional emulsion polymerization was carried out at $70^{\circ} \mathrm{C}$.

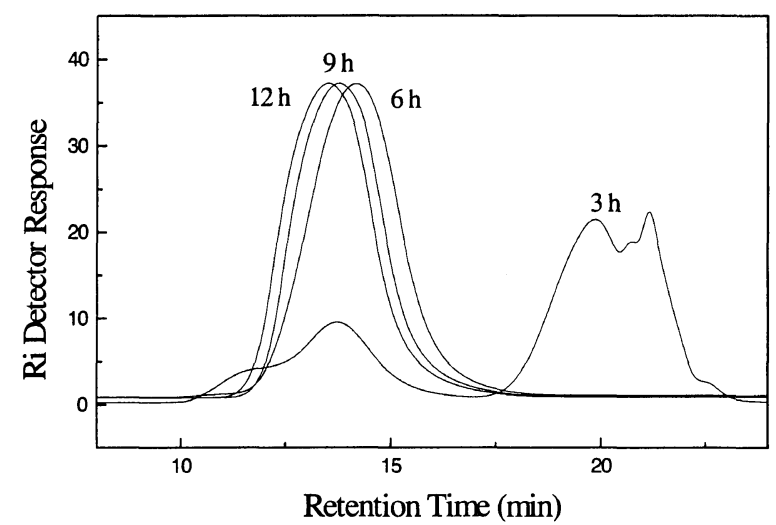

Figure 3. GPC traces in HTEMPO-mediated emulsion polymerization at $120^{\circ} \mathrm{C}$, in which $15.8 \mathrm{~g}$ styrene, $30 \mathrm{~g} \mathrm{H}_{2} \mathrm{O}, 0.105 \mathrm{~g}$ SDS, $0.1026 \mathrm{~g} \mathrm{~K}_{2} \mathrm{~S}_{2} \mathrm{O}_{8}$ has been used and $\left[\mathrm{K}_{2} \mathrm{~S}_{2} \mathrm{O}_{8}\right]_{0}:[\mathrm{HTEMPO}]_{0}=1: 1.1$.

erization of styrene in the presence of HTEMPO. The evolution of number-average molar mass $\left(M_{\mathrm{n}}\right)$ and polydispersity index $\left(M_{\mathrm{w}} / M_{\mathrm{n}}\right)$ with conversion and reaction time are shown in Table I. The experimental results show that the emulsion polymerization of styrene in the presence of HTEMPO is much slower than that in the presence of ATEMPO. For 3-h polymerization, the conversion is only about $1 \%$. Therefore, the GPC trace for oligomers is remarkable discerned and it will fade with reaction proceeds. The molecular weights of oligomers are too little to be checked by GPC in our lab. $M_{\mathrm{n}}$ for $3-\mathrm{h}$ polymerization provided in Table I is only for the purpose of comparison and all oligomers have been excluded in calculation. Afterwards, a relatively rapid polymerization happens. There is slight flocculation during the polymerization.

The results in Table I show that there is no characteristic of living polymerization for the emulsion polymerization of polystyrene in the presence of BTEMPO. In addition, there is coagulation during the emulsion polym-

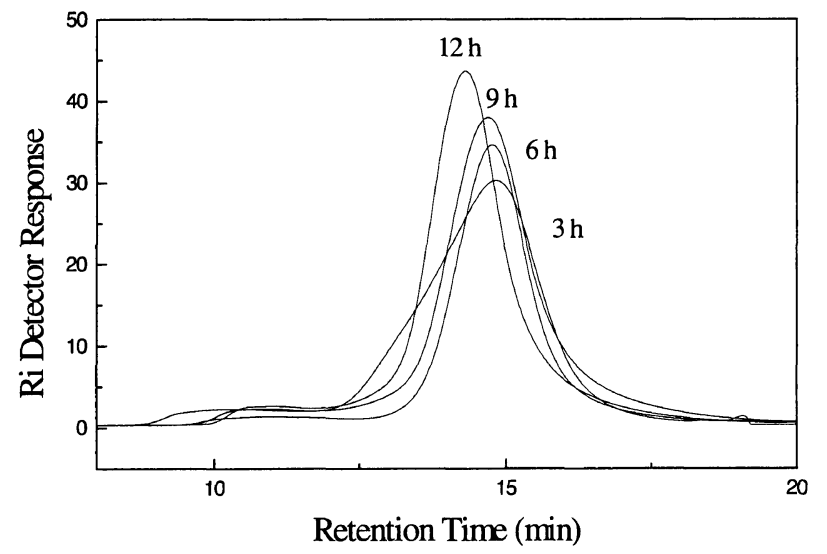

Figure 4. GPC traces in TEMPO-mediated emulsion polymerization at $120^{\circ} \mathrm{C}$, in which $15.8 \mathrm{~g}$ styrene, $30 \mathrm{~g} \mathrm{H}_{2} \mathrm{O}, 0.105 \mathrm{~g}$ SDS, $0.1026 \mathrm{~g} \mathrm{~K}_{2} \mathrm{~S}_{2} \mathrm{O}_{8}$ has been used and $\left[\mathrm{K}_{2} \mathrm{~S}_{2} \mathrm{O}_{8}\right]_{0}$ : [TEMPO $]_{0}=1: 1.1$.

erization of styrene in the presence of BTEMPO. The experimental results of TEMPO mediated emulsion polymerization of styrene are presented in Table I and Figure 4. Although TEMPO-mediated radical polymerization of styrene has been obtained much success in bulk, there is no obvious characteristic of a living polymerization in emulsion.

For $\mathrm{K}_{2} \mathrm{~S}_{2} \mathrm{O}_{8}$-initiated emulsion polymerization, the initiation starts at the decomposition of persulfate in aqueous (eq 2). ${ }^{25}$ The primary radicals dissociated from peroxydisulfates react with the tiny amount of monomers dissolved in aqueous phase firstly, yielding oligomeric radicals with aqueous-favoring sulfate ion group at end of chain and hydrophobic group at another end of chain. While the oligomer radical is propagating in the aqueous phase, it may also undergo termination with another radical specie. Subsequent aqueous phase propagation of oligomeric radicals which escape termination enables them to attain a critical degree of polymerization $z$ at which the species are now surface-active, the value of $z$ 
being about 3 for styrene. The resulting species become a micelle, either by entering a pre-existing micelle or by forming a micelle by aggregation with surfactant molecules in the aqueous phase. Afterwards, the oligomeric radicals enclosed in micelles propagate rapidly with monomers. The success of the model for entry described here must arise because only $z$-mers remain attached to the surface for a sufficiently long time that the undergo propagation in preference to the alternative fates of desorbing and then either termination or propagation in the aqueous phase.

$$
\begin{aligned}
& \mathrm{S}_{2} \mathrm{O}_{8}^{2-} \longrightarrow 2 \mathrm{SO}_{4}^{\bullet-} \\
& \mathrm{M}+\mathrm{SO}_{4}^{\bullet-} \longrightarrow{ }^{\bullet} \mathrm{MSO}_{4}^{-} \\
& { }^{\bullet} \mathrm{MSO}_{4}^{-}+\mathrm{M} \longrightarrow{ }^{\bullet} \mathrm{M}_{2} \mathrm{SO}_{4}^{-} \longrightarrow \bullet \bullet \longrightarrow{ }^{\bullet} \mathrm{M}_{z} \mathrm{SO}_{4}^{-} \\
& { }^{\bullet} \mathrm{M}_{i} \mathrm{SO}_{4}^{-}+\mathrm{M}_{j} \mathrm{SO}_{4}^{-} \longrightarrow \mathrm{M}_{i+j}\left(\mathrm{SO}_{4}\right)_{2}^{2-} \\
& \mathrm{M}_{z} \mathrm{SO}_{4}^{-}+\text {particle } \longrightarrow \text { entry }
\end{aligned}
$$

For the emulsion polymerization in the presence of SNRs, however, the additional reversible reactions between growing radicals and SNRs should affect the polymerization behavior to a great extent, whose locus should be decided by the hydrophilic and the hydrophobic character of SNRs. If SNRs are solved in aqueous phase, the reversible reaction between oligomeric radicals and SNRs in aqueous phase as a step of initiation should be seriously taken into account (eq 3). The most of oligomeric species entering into the latex particles are nitroxide-capped oligomers $\left(\mathrm{M}_{z^{\prime}} \mathrm{N}\right)$ rather than oligomeric radicals $\left(\mathrm{M}_{z}^{*}\right)$ due to the equilibrium of the reversible termination strongly tend to the dormant chains. In micelles the oligomeric radicals propagate with monomers released from nitroxide-capped oligomers. It is noted that the critical degree of polymerization $z^{\prime}$ for nitroxide-capped oligomer might be unequal to the critical degree of polymerization $z$ for oligomeric radical, because the value of $z$ is strongly influenced by the water-solubility of the oligomeric species. ${ }^{22}$

$$
\begin{aligned}
& \mathrm{N}^{\bullet}+{ }^{\bullet} \mathrm{M}_{n} \mathrm{SO}_{4}^{-} \frac{k_{\mathrm{f}}}{k_{-\mathrm{f}}} \mathrm{NM}_{n} \mathrm{SO}_{4}^{-} \\
& \mathrm{NM}_{z^{\prime}} \mathrm{SO}_{4}^{-}+\text {particle } \longrightarrow \text { entry }
\end{aligned}
$$

As above-mentioned, in emulsion the polymerization rate of HTEMPO-mediated radical polymerization of styrene is rather low than that of ATEMPO-mediated radical polymerization. Nevertheless, in bulk the polymerization rate of HTEMPO-mediated radical polymerization of styrene is close to that of ATEMPO-mediated radical polymerization of styrene (Figure 5). In bulk the polymerization rate of LFRP is strongly influenced by the equilibrium constant of the reversible termination between the dormant chains and the growing chain radicals. There is no obvious difference between HTEMPOmediated system and ATEMPO-mediated system. In emulsion, however, the polymerization rate is also influenced by the hydrophilic and the hydrophobic character

\begin{tabular}{|c|c|c|}
\hline \multirow{2}{*}{ Nitroxides } & \multicolumn{2}{|c|}{ Saturation Concentration } \\
\hline & in aqueous/g $\mathrm{L}^{-1}$ & in styrene/g L $\mathrm{L}^{-1}$ \\
\hline TEMPO & 10.3 & 290.2 \\
\hline ATEMPO & 27.9 & 178.0 \\
\hline BTEMPO $^{a}$ & - & 327.4 \\
\hline HTEMPO & 154.8 & 90.7 \\
\hline
\end{tabular}

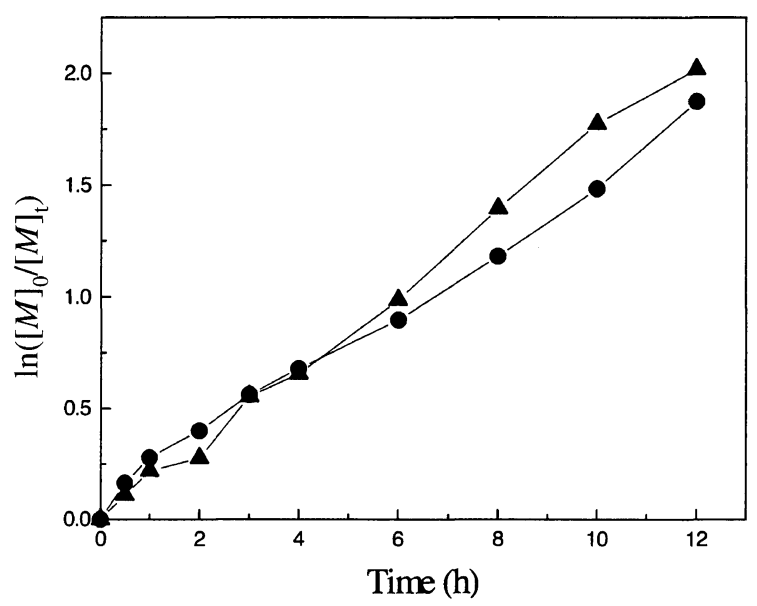

Figure 5. Kinetic plots of conversion vs. time for polymerization of styrene in bulk at $120^{\circ} \mathrm{C}$ with $[\mathrm{AIBN}]_{0}=0.25 \%[\mathrm{St}]_{0}$, [SNRs] $]_{\mathrm{o}}^{\prime}$ $[\mathrm{AIBN}]_{0}=1.1: 1$, in the presence of HTEMPO (O) and ATEMPO $(\boldsymbol{\Delta})$.

Table II. The saturation concentration of TEMPO and TEMPO derivatives in aqueous and styrene $\left(25^{\circ} \mathrm{C}\right)$

${ }^{\text {a }}$ The saturation concentration of BTEMPO in aqueous is too low to be measured by UV-spectroscopy.

of SNRs. HTEMPO is regarded as being rich in aqueous phase due to its hydroxyl group (Table II). In fact, we have observed the color of water layer was orange and that of monomer layer was rather pale, as the mixture of styrene and water solved with HTEMPO was stayed for a period. ESR analysis also suggested that most of HTEMPO is located in aqueous phase. ${ }^{18}$ With the reversible reaction controlled by the large amount of HTEMPO in aqueous phase, it will take long time for oligmers to reach the enough number-average molar mass of entering to latex particles, resulting the slow overall polymerization and low conversion with a lot of oligomers in the early stage of reaction (Table I and Figure 3). Moreover, the oligomers with HTEMPO at the end-group is hydrophilic, this again favoring the species remaining in the aqueous phase and the value of $z$ will be greater. In this case the probability of termination in aqueous will be increased, which is not in favor of the living fashion.

Among the nitroxides we investigated, BTEMPO is a typical organic-riched SNR. After the mixture of styrene and water with BTEMPO was stayed for a period,the color of monomer layer was orange which is the typical color of TEMPO derivatives, while no color in water layer. In fact it is almost no BTEMPO solved in water when we try to solve it in order to measure the saturation concentration by UV-spectroscopy. Till now no data of the saturation concentration of BTEMPO has been reported. According to Wang et al., ${ }^{26}$ the saturation concentration of TEMPO derivatives in aqueous decreases 
with the increase of the steric hindrance of substituting group. For example, the saturation concentration of 4octanoyl-2,2,6,6-tetramethylpeperidine-1-oxy (C 8TEMPO) in aqueous is $c a .4 \times 10^{-5} \mathrm{M}$, while that of 4dodecanoyl-2,2,6,6-tetramethylpiperidine-1-oxy (C 12TEMPO) is ca. $4 \times 10^{-6} \mathrm{M}$. This could help us to understand why BTEMPO is hard to be solved in water phase. As a result, almost all BTEMPO distribute in monomer droplets and the reversible reaction could be negligible. In this case the emulsion polymerization is uncontrolled and identical to conventional radical emulsion polymerization. Compared to that of BTEMPO, the solubility of TEMPO in aqueous phase is remarkable (Table II), however, it might be still too low to support a successful living radical emulsion polymerization at present work.

Among the nitroxide-mediated radical polymerization in emulsion we studied, ATEMPO-mediated system is more close to an ideal living radical polymerization than the others. This is because an optimized balance between the hydrophilic and the hydrophobic character of SNRs contributes to a living radical polymerization in emulsion (Table II). We found both the monomer layer and the water layer show orange color in spite the color of water phase is paler than that of monomer phase, when the mixture of styrene and water solved with ATEMPO was stayed for a period. With relatively lower concentration of SNRs in aqueous phase, it will take less time for oligmeric species in ATEMPO-mediated system to reach the critical degree of polymerization of entering to micelles than that in HTEMPO-mediated system, resulting a quicker overall polymerization rate.

We also investigate the emulsion polymerization of styrene in the presence of different ratio of ATEMPO to $\mathrm{K}_{2} \mathrm{~S}_{2} \mathrm{O}_{8}$. Figure 6 shows that the polymerization rate increases with the decrease of ATEMPO. However, the value of polydispersity of product increases obviously (Table III). Figure 7 presents the GPC trace of polystyrene in the emulsion polymerization with different ratio of ATEMPO to $\mathrm{K}_{2} \mathrm{~S}_{2} \mathrm{O}_{8}$. A minor peak corresponding to high molecular weight, which is ascribed to the uncontrolled chain growth at initial stage of reaction, is evidently discerned for ATEMPO/ $\mathrm{K}_{2} \mathrm{~S}_{2} \mathrm{O}_{8}=1.5: 1$, because the conversion is still low after $12 \mathrm{~h}$ of reaction (Table III). The above results indicate that the feed ratio of ATEMPO to $\mathrm{K}_{2} \mathrm{~S}_{2} \mathrm{O}_{8}$ should be carefully chosen for designing a living radical emulsion polymerization.

The morphology of styrene particles in ATEMPOmediated and HTEMPO-mediated radical polymerization in emulsion after $12 \mathrm{~h}$ of reaction is presented in Figure 8 . The number average particle size of styrene particles after $12 \mathrm{~h}$ of reaction is $65 \mathrm{~nm}$ for the ATEMPO-mediated system and $46 \mathrm{~nm}$ for the HTEMPO-mediated system, respectively. For comparison, the conventional emulsion polymerization was carried out at $70^{\circ} \mathrm{C}$ for $2 \mathrm{~h}$ and the corresponding recipe was the same as that in nitroxide-mediated emulsion polymerization except that SNRs were excluded. The number average particle size is $208 \mathrm{~nm}$ for the conventional emulsion polymerization. The morphology of HTEMPOmediated system is similar to that of ATEMPOmediated system in spite of the smaller particle size. As shown in Figure 8, the particles of ATEMPO-mediated system have shown good regularity even compared to

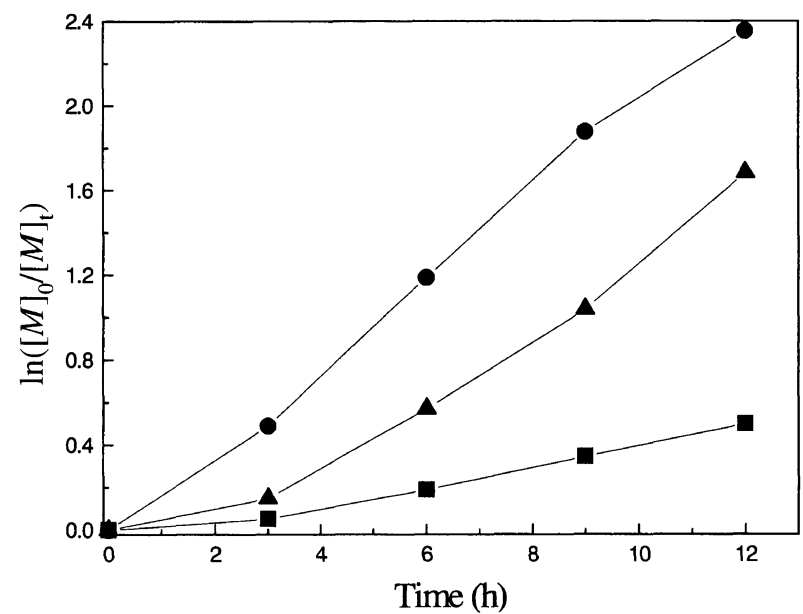

Figure 6. Kinetic plots of conversion vs. time for polymerization of styrene in emulsion at $120^{\circ} \mathrm{C}$ with $15.8 \mathrm{~g}$ styrene, $30 \mathrm{~g} \mathrm{H}_{2} \mathrm{O}$, $0.105 \mathrm{~g}$ SDS, $0.1026 \mathrm{~g} \mathrm{~K}_{2} \mathrm{~S}_{2} \mathrm{O}_{8}$, in which $\left[\mathrm{K}_{2} \mathrm{~S}_{2} \mathrm{O}_{8}\right]_{0}:[\mathrm{ATEMPO}]_{0}=1$ : $0.8(\mathbf{O}), 1: 1.1(\boldsymbol{\Delta})$, and 1:1.5 ( $\square$ ), respectively.

Table III. ATEMPO-mediated radical polymerization of styrene in emulsion (12 h)

\begin{tabular}{ccccc}
\hline ATEMPO/ $\mathrm{K}_{2} \mathrm{~S}_{2} \mathrm{O}_{8}$ & & Conversion & & $M_{\mathrm{n}}$ \\
\cline { 1 - 1 } mole ratio & & & $M_{\mathrm{w}} / M_{\mathrm{n}}$ \\
\hline $0.8: 1$ & 90.51 & 23100 & 2.24 \\
$1.1: 1$ & 81.42 & 17900 & 1.29 \\
$1.5: 1$ & 39.31 & 7200 & 1.36 \\
\hline
\end{tabular}

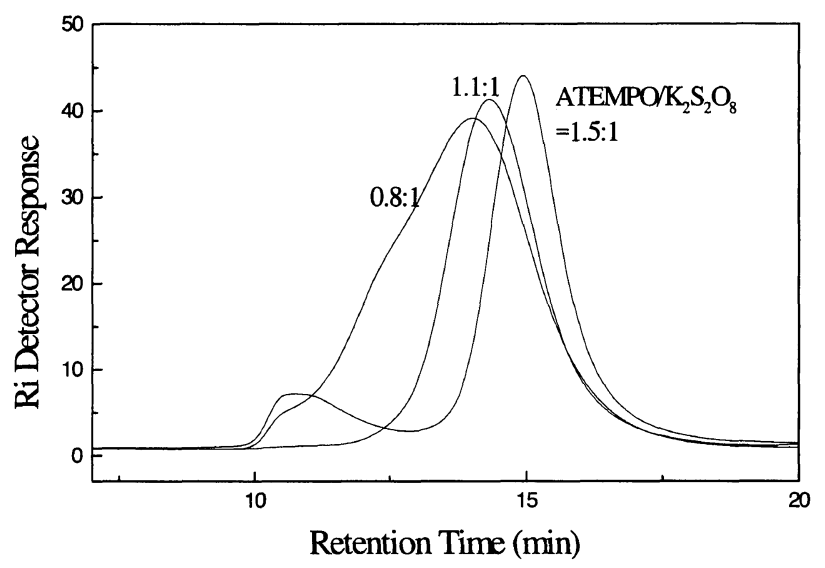

Figure 7. GPC traces in emulsion polymerization of styrene at $120^{\circ} \mathrm{C}$, in which $15.8 \mathrm{~g}$ styrene, $30 \mathrm{~g} \mathrm{H}_{2} \mathrm{O}, 0.105 \mathrm{~g}$ SDS, and 0.1026 $\mathrm{g} \mathrm{K}_{2} \mathrm{~S}_{2} \mathrm{O}_{8}$ has been used, $\left[\mathrm{K}_{2} \mathrm{~S}_{2} \mathrm{O}_{8}\right]_{0}:$ [ATEMPO] $]_{0}=1: 0.8,1: 1.1$, and $1: 1.5$, respectively.

that of conventional system in the given experimental conditions. Guyot et al. ${ }^{14}$ suggested that SDS was hydrolyzed during the long reaction time, giving rise to dodecanol, which is a key factor to latex stabilization. To reveal the morphology change related to the polymerization mechanism, more detailed experiments will be reported in the further works.

\section{CONCLUSIONS}

In this paper we carried out the emulsion polymerizations of styrene in the presence of a variety of TEMPO 


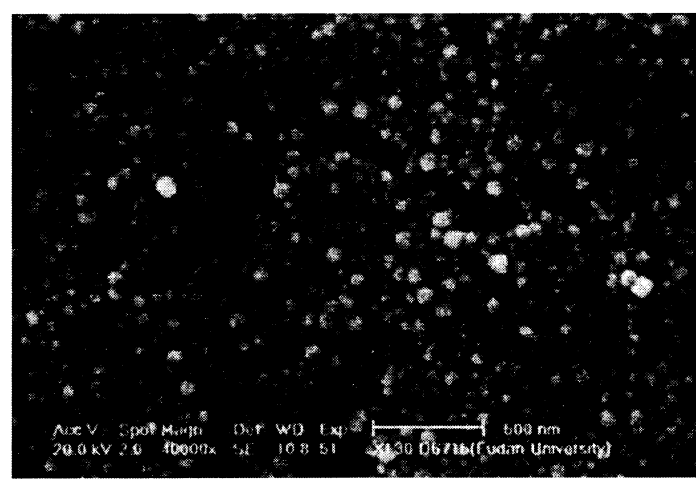

(a)

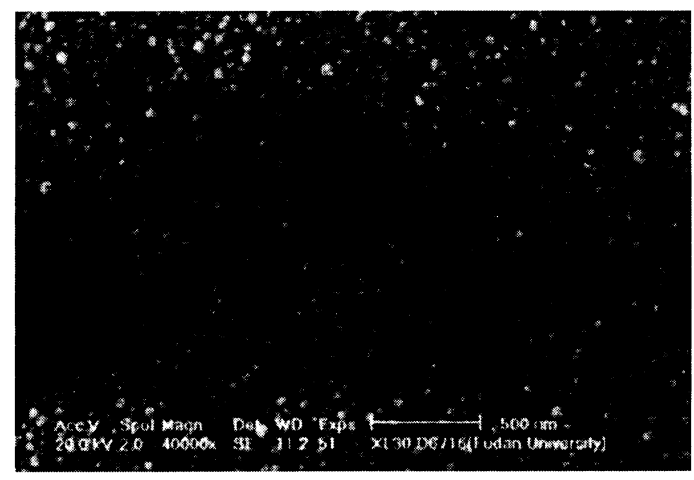

(b)

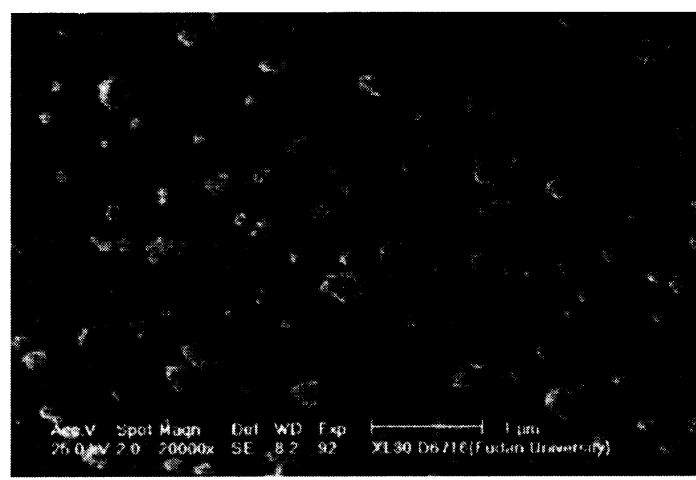

(c)

Figure 8. SEM photographs of particles in emulsion polymerization of styrene for (a) ATEMPO-mediated system $(\times 40000)$; (b) HTEMPO-mediated system $(\times 40000)$ and $(c)$ conventional emulsion polymerization $(\times 20000)$.

derivatives to investigate the mechanism of nitroxidemediated radical polymerization in emulsion. ATEMPO is prior to HTEMPO and BTEMPO in mediating the radical polymerization of styrene in emulsion. The results show that an optimized balance between the hydrophilic and the hydrophobic character of TEMPO derivatives is the key of a successful living radical polymerization in emulsion.

Furthermore, on the nitroxide-controlled emulsion po- lymerization initiated by oil soluble initiator, the effect of surfactant and initiator on the mechanism and kinetics of nitroxide-controlled radical polymerization in emulsion will be discussed elsewhere.

Acknowledgments. The authors gratefully acknowledge the financial support and the kindful donation of a Waters GPC Instrument and 4-hydroxyl-TEMPO of the BASF Corp. of Germany. We would like to thank the Special Funds for Major State Basic Research Projects (G1999064800), NSFC (20004001) and EYTP of MOE, P. R. C.

\section{REFERENCES}

1. M. K. Georges, R. P. N. Veregin, P. M. Kazmaier, and G. K. Hamer, Trends Polym. Sci., 2, 66 (1994).

2. C. J. Hawker, J. Am. Chem. Soc., 116, 11314 (1994).

3. C. J. Hawker and J. L. Hedrick, Macromolecules, 28, 2993 (1995).

4. S. Gaynor, S. Edelman, and K. Matyjaszewski, Macromolecules, 28, 6381 (1995).

5. M. R. Leduc, C. J. Hawker, J. Dao, and J. M. J. Frechet, J. Am. Chem. Soc., 118, 11111 (1996).

6. C. J. Hawker, Acc. Chem. Res., 30, 373 (1997).

7. M. Baumert, H. Frey, M. Hoelderle, J. Kressler, F. G. Sernetz, and R. Muelhaupt, Macromol. Symp., 121, 53 (1998).

8. C. J. Hawker, Angew Chem., Int. Ed., 34, 1456 (1995).

9. M. K. Georges, R. P. N. Veregin, G. K. Hamer, and P. M. Kazmaier, Macromol. Symp., 88, 89 (1994).

10. G. Schmidt-Naake, M. Drache, and C. Taube, Angew. Makromol. Chem., 265, 62 (1999).

11. C. Taube and G. Schmidt-Naake, Makromol. Mater. \& Eng., 279, 26 (2000).

12. T. Nishikawa, M. Kamigaito, and M. Sawamoto, Macromolecules, 32, 2204 (1999).

13. L. I. Gabaston, P. A. Jackson, and S. P. Armes, Macromolecules, 31, 2883 (1998).

14. S. G. Gaynor, J. Qiu, D. Shipp, and K. Matyjaszewski, Polym. Mater. Sci. Eng., 80, 536 (1999).

15. D. Charmot, P. Corpart, H. Adam, S. Z. Zard, T. Biadatti, and G. Bouhadir, Macromol. Symp., 150, 23 (2000).

16. S. A. F. Bon, M. Bosveld, B. Klumperman, and A. L. German, Macromolecules, 30, 324 (1997).

17. M. Bouix, J. Gouzi, B. Charleux, J.-P. Vairon, and P. Guinot, Macromol. Rapid Commun., 19, 209 (1998).

18. C. Marestin, C. C. Noël, A. Guyot, and J. Claverie, Macromolecules, 31, 4041 (1998)

19. J. Qiu, S. G. Gaynor, and K. Matyjaszewski, Macromolecules, 32, 2872 (1999).

20. T. Prodpran, V. L. Dimonie, E. D. Sudol, and M. S. El-Aasser, Macromol. Symp., 155, 1 (2000).

21. P.J. MacLeod, R. Barber, P. G. Odell, B. Keoshkerian, and M. K. Georges, Macromol. Symp., 155, 31 (2000).

22. F. K. Hansen, E. B. Ofstad, and J. Ugelstad, "Theory and Practice of Emulsion Technology", Academic Press, New York, N.Y., 1976, Chapter 1.

23. E. G. Rozantsev, "Free Nitroxyl Radicals", Plenum Press, New York-London, 1970, Chapter 9.

24. D. Colombani, Prog. Polym. Sci., 22, 1649 (1997).

25. R. G. Gilbert, "Emulsion Polymerization: A Mechanism Approach", Academic Press, London, 1995, Chapter 4.

26. Y. Wang, D. Lu, C. Long, B. Han, and H. Yan, Langmuir, 14, 2050 (1998) 